valve closure on ultrasound, and systolic anterior movement of the anterior mitral cusp. Hypertrophic cardiomyopathy is seen in infants of diabetic mothers, Pompe's disease, and Friedreich's ataxia, and there is often a strong familial tendency. Maron et al. ${ }^{5}$ reported 46 cases in childhood of asymmetric septal hypertrophy and noted the high incidence of sudden death $(30 \%)$ especially in those with overt heart disease. They could not predict those at risk on the basis of echocardiogram, ECG, left ventricular function, or outflow obstruction. Betablockers or surgery in selected patients did not reduce mortality.

Rigid spine syndrome is of unknown aetiology. In earlier reports it was associated with a good prognosis. The association with hypertrophic cardiomyopathy indicates that the prognosis may not always be good and may support the idea that the syndrome is a disorder of muscle rather than of bone, nerve, or connective tissue. ment, Royal Hospital for Sick Children, and Miss M McKenna and Mrs J Clark, Department of Child Life and Health, for help.

\section{References}

1 Dubowitz V. Muscle disorders in childhood. Philadelphia: Saunders, 1978: 239-43.

2 Seay A R, Ziter F A, Petajan J H. Rigid spine syndrome. A type I fiber myopathy. Arch Neurol 1977; 34: 119-22.

3 Goebel H H, Lenard H G, Gorke W, Kunze K. Fibre type disproportion in the rigid spine syndrome. Neuropaediatrie $1977 ; 8$ : 467-77.

4 Bradley W G, Hudgson P, Gardner-Medwin D, Walton J N. The syndrome of myosclerosis. J Neurol Neurosurg Psychiatry 1973; 36: 651-60.

5 Maron B J, Henry W L, Clark C E, Redwood D R, Roberts W C, Epstein S E. Asymmetric septal hypertrophy in childhood. Circulation 1976; 53: 9-19.

Correspondence to Dr W S Uttley, Department of Child Life and Health, 17 Hatton Place, Edinburgh EH9 1 UW.

Received 6 November 1979

We thank Mr L Cumming, Photography Depart-

\title{
Screening for cystic fibrosis by a stool trypsin method
}

\section{C FORREST, BRIDGET WILCKEN, AND GILLIAN TURNER}

Oliver Latham Laboratory, Health Commission of New South Wales, Sydney, and Prince of Wales Children's Hospital, Randwick, Sydney, Australia

SUMMARY Mass screening for cystic fibrosis by a trypsin assay of stool dried on filter paper was evaluated in 20000 -day-old babies. Sweat tests were required in only 7 babies. Three of them had cystic fibrosis. The test gave a false-negative result in at least 2 babies, but each had normal pancreatic function. This is not an ideal screening test for cystic fibrosis, as it misses cases with normal pancreatic function, but it is very cheap, highly specific, and appears to be the best currently available screening test.

A screening method for cystic fibrosis has long been sought. Of methods based on an assay of pancreatic function, those using meconium are inconvenient: a second sample cannot be obtained, the test cannot be performed at a central laboratory, and all have had reports of high false-positive and false-negative rates. ${ }^{1-2}$ The method of Crossley et al., ${ }^{3}$ which assays stool trypsin content, seemed sufficiently promising for a large-scale evaluation, as samples could be sent by post, and repeat samples obtained noninvasively.

We conducted a study in New South Wales, Australia to evaluate Crossley's method of screening, and this paper reports the results.

\section{Samples and methods}

Stool samples from 20000 5-day-old babies were collected on to filter paper, dried, and posted to the laboratory. Five Sydney and 20 country hospitals took part in the project which lasted a year and so included the hot summer months.

The method of Crossley et al. ${ }^{3}$ was used to assay trypsin activity. Discs $6 \mathrm{~mm}$ in diameter were punched from faeces-impregnated filter paper, incubated overnight with benzoyl-L-arginine-pnitroanilide hydrochloride (L-BAPNA). Trypsin present in samples cleaves a yellow p-nitroanilide molecule from the L-BAPNA. Samples deficient in trypsin remain colourless or very pale yellow. The test result can be read by eye. If the yellow colour was 
absent or not strong, the optical density (OD) was measured at 410 and $460 \mathrm{~nm}$, as described by Crossley et al., and samples with $\mathrm{OD}_{410}-2\left(\mathrm{OD}_{460}\right)$ of less than $0 \cdot 3$ were reassayed using two $6 \mathrm{~mm}$ discs. If samples gave a positive result (lack of trypsin activity) on reassay, a second stool sample was obtained by writing to the mother. If the second stool sample showed lack of trypsin activity too, the baby's doctor was asked to arrange for a sweat test to be carried out.

In addition, samples from 17 newly diagnosed and untreated patients with cystic fibrosis were obtained and tested in the same manner.

To assess the stability of trypsin activity in the samples, 30 samples were assayed before and after being exposed for 5 days to temperatures of either $18^{\circ} \mathrm{C}$ or $34^{\circ} \mathrm{C}$ in either ambient humidity, or humidity close to $100 \%$ saturation.

\section{Results}

Newborn population. Resampling was necessary in $0.53 \%$ of cases because each first sample was repeatedly positive. $93 \%$ of second samples were received, but the remaining $7 \%$ could not be obtained despite three requests.

Seven of the second samples had deficient trypsin activity, and sweat tests were performed on these babies. Two sweat tests were positive, and both the babies had cystic fibrosis. In one the sweat test was inconclusive: there were high electrolyte levels but insufficient sweat was collected. This baby, a sibling of a patient known to have cystic fibrosis, died with symptoms that could have been due to cystic fibrosis. The 4 remaining sweat tests gave negative results.

Two babies whose stool trypsin screening test was normal were subsequently diagnosed as having cystic fibrosis. Neither required pancreatic enzyme supplementation.

The false-positive rate in our survey was thus $0.53 \%$ after the first sample, and $0.02 \%$ after the second sample, 4 in 19997 cases, and the falsenegative rate at least $40 \%$ ( 2 of at least 5 cases). However, no false-negative result has yet been known to have been obtained in a patient whose pancreatic function is deficient.

Cystic fibrosis cases, before treatment. Of 17 stool samples from known cystic fibrosis patients, a positive test result was obtained in 13 , indicating deficient trypsin activity. The 4 samples which gave a negative (normal) result came from patients whose pancreatic function was adequate at the time.

Cost of the test. The cost of testing each baby was 11 cents (about £0.06) for clerical and technical time, chemicals, and glassware.
Stability of trypsin activity. Optical densities at 410 and $460 \mathrm{~nm}$ of samples before and after heating for 5 days at $18^{\circ} \mathrm{C}$ or $34^{\circ} \mathrm{C}$ in moist or relatively dry conditions were not significantly altered.

\section{Discussion}

The purpose of this study was to evaluate the sensitivity and specificity of the stool trypsin method of screening for cystic fibrosis, and to discover how easily it could be implemented in our health organisation.

The specificity of the test was fairly satisfactory. The false-positive rate on the initial assay, $0.53 \%$, was much higher than the $0.1 \%$ found by Crossley et al., but the false-positive rate on the second sample was lower $(0.02$ versus $0.05 \%)$. Thus, although fewer unnecessary sweat tests had to be performed, the rate of resampling was rather higher. Crossley et al. noted that most false-positive results on the first sample appeared to be associated with prematurity in the babies, but our data did not give sufficient information about this. If the initial test could be carried out efficiently at, say, age 2 weeks, with sample collection arranged by local baby health centres, the specificity of the test would be likely to be much higher.

In our study, the sensitivity of the test was not good. We identified only 3 cases of cystic fibrosis in 20000 patients, and 2 cases ascertained because of symptoms had had false-negative results. This total of 5 patients was about half that expected, and our false-negative rate may well prove to be higher. However, those cases we missed were patients whose pancreatic function at the time of diagnosis was adequate, and we would therefore have expected the test result to be negative in such cases.

No problems were encountered in setting up this pilot screening programme, and hospital staff had no difficulties in following sample collection instructions. The cost of performing the test was very low\$A $0 \cdot 11$ per baby - but no account was taken of costs associated with collection or dispatch. Nevertheless, it is certain that in Australia the cost would compare very favourably with that of using any commercial kit for meconium testing currently available on the Australian market.

Crossley et al. have recently described a blood spot method of screening for cystic fibrosis. ${ }^{4}$ If, when larger numbers of newborn infants have been studied, this proves to be a test with high specificity and sensitivity, it will be a significant advance in screening for cystic fibrosis. In the meantime although the stool trypsin method is not an ideal screening test, missing as it does those patients with normally functioning pancreata, in view of its cheapness, its 
noninvasiveness, its low false-positive rate, its robustness, and simplicity it should be seriously considered as a possible method of screening for cystic fibrosis. It appears to be the best method currently available.

D C F was supported by the Cystic Fibrosis Association of New South Wales.

\section{References}

1 Stephan U, Busch E W, Kollberg H, Hellsing K. Cystic fibrosis detection by means of a test strip. Pediatrics 1975; 55: $35-8$.
2 Schuttringer G, Zinterhofer L. Automated immunoprecipitation of meconium albumin for cystic fibrosis screening in the newborn. Clin Chim Acta 1978; 83: 109-16.

3 Crossley J R, Berryman C C, Elliott R B. Cystic fibrosis screening in the newborn. Lancet 1977; ii: 1093-5.

4 Crossley J R, Elliott R B, Smith P A. Dried blood-spot screening for cystic fibrosis in the newborn. Lancet 1979; i: $472-4$.

Correspondence to Dr Bridget Wilcken, NSW Newborn Screening Programme, Oliver Latham Laboratory, Box 53, North Ryde, New South Wales 2113, Australia.

Received 5 February 1980

\title{
Upper airways obstruction
}

\section{Presentation with systemic hypertension}

\author{
MARIA SERRATTO, VIVIAN J HARRIS, AND IAN CARR
}

Department of Pediatric Cardiology and Department of Pediatric Radiology, Cook County Children's Hospital, and the Hektoen Institute for Medical Research, Chicago, USA

SUMMARY Of 14 patients whose final diagnosis was upper airways obstruction associated with heart failure, 3 presented with systemic hypertension (up to $200 / 100 \mathrm{mmHg}$ ). In 2 the hypertension was so severe that at first it had to be considered as a possible cause of the presenting symptoms. The subsequent history indicated that it was an effect of the upper airways obstruction with heart failure.

Upper airways obstruction can lead to pulmonary arteriolar vasoconstriction, pulmonary arterial hypertension, cor pulmonale, and right heart failure. ${ }^{1-4}$ We describe 3 children who were part of a group of 14 children who presented consecutively with upper airways obstruction associated with heart failure.

\section{Case report}

Case 1. A 2-year-old boy was admitted to hospital, semi-comatose, with a 3-day history of upper respiratory infection. Blood pressure (BP) was $160 / 120 \mathrm{mmHg}^{*}$ and there were signs of severe congestive heart failure. Chest $x$-ray film showed

\footnotetext{
*The equipment used in this and in the subsequent cases was a standard mercury sphygmomanometer and a cuff that covered at least two-thirds of the upper arm. Systolic and diastolic pressures were recorded at the appearance and disappearance (first and fifth phases) of Korotkoff's sounds.
}

gross cardiomegaly and signs of pulmonary oedema. Electrocardiogram (ECG) showed a normal QRS axis of $+70^{\circ}$, right atrial P-waves, and left ventricular hypertrophy pattern. He was treated with intravenous diuretics and digitalis, and was given artificial ventilation using a respirator. Before artificial ventilation arterial $\mathrm{PCO}_{2}$ was $72.5 \mathrm{mmHg}$ $(9 \cdot 6 \mathrm{kPa}), \mathrm{Po}_{2} 63.6 \mathrm{mmHg}(8 \cdot 5 \mathrm{kPa})$, and $\mathrm{pH} 7 \cdot 23$. After 3 hours of artificial ventilation, $\mathrm{PCO}_{2}$ was $46 \mathrm{mmHg}(6 \cdot 1 \mathrm{kPa}), \mathrm{Po}_{2} 149 \cdot 5 \mathrm{mmHg}(19 \cdot 9 \mathrm{kPa})$, and $\mathrm{pH} 7 \cdot 45$. BP remained high $(150 / 120 \mathrm{mmHg})$ and he remained semi-comatose. His fundi were normal but a lumbar puncture showed an opening pressure of $400 \mathrm{~mm}$ cerebrospinal fluid. BP fell after antihypertensive medication. By day 3 he was awake with no respiratory distress and his BP had stabilised (about $110 / 60 \mathrm{mmHg}$ ) without treatment. Renal arteriogram and vanillyl-mandelic acid (VMA) levels $(0.7 \mathrm{mg} / 24 \mathrm{~h})$ were normal. Because of large tonsils and adenoids it was felt that upper airways obstruction might be responsible for the symptoms, and removal of tonsils and adenoids was planned but the appointment was not kept.

The boy did not return until age $3 \frac{1}{2}$ when he was again admitted with a'history of upper respiratory infection, in severe "respiratory distress, semicomatose, and in congestive heart failure. Again he recovered, removal of tonsils and adenoids was again planned, but again the appointment was not kept. $\mathrm{He}$ 